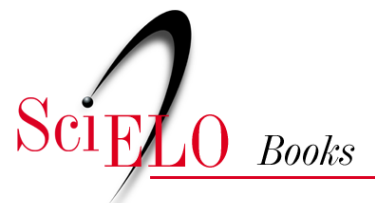

\title{
2. A bioética e suas teorias
}

\author{
Sergio Rego \\ Marisa Palácios \\ Rodrigo Siqueira-Batista
}

\section{SciELO Books / SciELO Livros / SciELO Libros}

REGO, S., PALÁCIOS, M., and SIQUEIRA-BATISTA, R. A bioética e suas teorias. In: Bioética para profissionais da saúde [online]. Rio de Janeiro: Editora FIOCRUZ, 2009. Temas em Saúde collection, pp. 39-62. ISBN: 978-85-7541-390-6. https://doi.org/10.7476/9788575413906.0003.

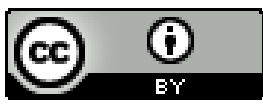

All the contents of this work, except where otherwise noted, is licensed under a Creative Commons Attribution 4.0 International license.

Todo o conteúdo deste trabalho, exceto quando houver ressalva, é publicado sob a licença Creative Commons Atribição 4.0. 


\section{2।a BioÉtica e suas Teorias}

A bioética tem se desenvolvido de modo extremamente veloz desde a sua origem, na segunda metade do século XX reconhecendo-se a publicação do trabalho de Potter como o marco de seu 'nascimento' -, com substantivo desenvolvimento de correntes e modelos.

Para abordagem dessa temática - mote do presente capítulo -, consideremos o seguinte caso: "A decisão do dr. Arnaldo: quem sobe?".

$\mathrm{O}$ dr. Arnaldo é médico residente de cirurgia geral em um hospital situado em um grande centro urbano. Durante seu plantão na emergência, no início de uma madrugada, dois pacientes baleados foram admitidos no hospital. O que foi trazido pelo Sistema de Atendimento de Urgência Municipal, Denílson, é um policial militar de 48 anos, ferido quando tentava impedir um assalto a um casal de namorados. O outro, José, 19 anos, trazido no carro de patrulhamento ostensivo da polícia, é o homem suspeito de ter alvejado o policial e que havia sido baleado por este. Ambos apresentam quadro clínico instável, precisando ser submetidos a um procedimento cirúrgico de urgência, mas o estado de José é mais grave. O residente determina à equipe de enfermagem que encaminhe os dois ao centro cirúrgico, mas é informado de que só há uma mesa cirúrgica disponível pelas próximas quatro horas. Só um poderá ser operado com todos os 
recursos do e no centro cirúrgico; o outro deverá ser operado na própria emergência ou aguardar a liberação de uma sala cirúrgica. A decisão tem que ser tomada imediatamente. O médico pensa por alguns instantes e decide encaminhar o policial ao centro cirúrgico.

O dr. Arnaldo tomou a decisão certa ou errada? É possível concordar ou discordar da decisão tomada por ele? Por quê?

A análise de um caso exemplo é o que propomos neste capítulo, tendo em vista sua aplicação na apreciação de algumas das teorias mais utilizadas em bioética. Esperamos tornar claro, em termos práticos, o modo como se utilizam os referenciais teóricos de bioética na prática em saúde. Todavia, é preciso, antes, fazer um alerta óbvio, mas não dispensável: as presentes descrições das correntes sofrem as limitações relativas ao espaço e ao objetivo do livro. Por isso, recomendamos fortemente que sejam consideradas as sugestões de leitura apresentadas ao final deste volume para o aprofundamento dos conhecimentos sobre as correntes. Vejamos, pois, como as questões morais interferem na tomada de decisão no caso concreto.

Qual seria a solução técnica para esse caso? E qual é o verdadeiro limite para o uso apenas do chamado 'saber técnico', ou 'profissional', no caso? Por mais que possamos questionar, por meio da técnica, as possibilidades de se estimar com segurança as chances de vida ou de morte de qualquer paciente, é factível para o médico avaliar as suas condições clínicas e informar, de acordo com o conhecimento clínico-epidemiológico, as probabilidades tanto da sobrevida em si quanto de sua qualidade. Essas probabilidades, mesmo que teóricas - ou seja, a aplicação ao caso implica a assunção de muitos graus de incerteza -, são 
ainda indicadores, dados concretos, e é razoável utilizá-las mantendo-se claro o limite de sua aplicação aos casos concretos. $\mathrm{Na}$ situação concreta, é possível que o profissional da saúde tenha clareza, mediante a avaliação clínica, sobre qual dos quadros é mais grave. A decisão de intervir sobre o caso mais grave já não é uma decisão técnica isenta de questões morais (ver as relações da bioética com os outros saberes no Capítulo 1). Por que operar aquele cujo estado é mais grave?

Será que a opção foi operar o paciente em estado menos grave porque ele teria mais chances de sobreviver do que aquele em situação mais grave? Será que a escolha se justifica porque o bandido é o que menos contribui para o bem-estar da sociedade? O policial, afinal, presta um serviço relevante à coletividade. Então... Será possível buscar, nas diferentes correntes da bioética, argumentos que sustentem ou critiquem a decisão do dr. Arnaldo?

\section{Principialismo}

O principialismo foi a primeira corrente bioética a se estruturar. As condições históricas que estão na base da sua constituição tiveram como um dos marcos o Relatório Belmont, publicado em 1978 como resultado do trabalho desenvolvido pela National Commission for the Protection of Human Subjects of Biomedical and Behavioral Research, criada pelo governo dos Estados Unidos em 1974. Essa comissão foi constituída após a denúncia da pesquisa com homens negros sifilíticos, em Tuskegee - a qual coroou uma série de escândalos em pesquisas com seres humanos -, e teve como incumbência definir que princípios deveriam orientar a realização de tais estudos. Como resultado de seu trabalho, a comissão propôs a observância de três princípios básicos, gerais, 
que orientariam as regras para proteção dos humanos em situação de pesquisa: o respeito pelas pessoas, a beneficência e a justiça. Ao contrário do que muitos imaginam, o trabalho realizado por Beauchamp e Childress (2002) não foi elaborado depois da conclusão do Relatório Belmont. Segundo Beauchamp, sua incorporação ao grupo de Belmont só se deu depois que a redação do livro estava bem adiantada, o que não impediu que um trabalho influenciasse o outro. Tal livro, Principles of Biomedical Ethics [Princípios da Ética Biomédica, versão em português já disponível], sistematiza, para o campo da prática biomédica, os princípios prima facie - princípios não absolutos que são igualmente válidos, em um primeiro momento, devendo pois ser cotejados, criteriosamente, para solução do problema - que foram apresentados para a prática da pesquisa científica. Nele, o respeito às pessoas foi definido como o respeito à autonomia das pessoas, o dever de agir com justiça, e a obrigação de fazer o bem foi desdobrada, sendo expressa a obrigação de não causar dano.

\section{Características do principialismo}

O que caracteriza as abordagens principialistas (ou seja, baseadas em princípios) é o reconhecimento de um mínimo de normas morais centrais, com base nas quais se procede ao julgamento da eticidade de uma ação. O foco central da abordagem são os princípios morais que orientam a ação. Normas morais (princípios e regras) são diretrizes gerais para a ação que especificam que determinadas ações são proibidas, requeridas ou permitidas em determinadas circunstâncias. A diferença entre princípios e regras está em que princípios são as diretrizes mais gerais e as regras são mais específicas. 
$\mathrm{Na}$ abordagem principialista - de acordo com o proposto por Beauchamp e Childress (2002), base para este texto - compreende-se que a ação eticamente adequada é aquela que se orienta por princípios morais universalmente aceitos. São considerados princípios fundamentais a beneficência, a não maleficência, o respeito à autonomia e a justiça. Não representam uma novidade em si, visto que é possível reconhecê-los nos ideais da Revolução Francesa - liberdade, igualdade e fraternidade - e mesmo no pensamento helênico antigo - ou seja, as obrigações de 'primeiro não causar dano' e de 'fazer o bem' da tradição médica hipocrática, ou ainda mais remotamente. Desses princípios centrais podem ser derivadas regras específicas, tais como: dizer a verdade; cumprir suas promessas; proteger a privacidade do paciente; não passar adiante informações que foram dadas em confiança; obter consentimento sempre - no cuidado e na pesquisa -, entre outros. Esses são exemplos de regras cuja validade dificilmente alguém poderia negar. São regras morais já consagradas na prática em saúde. Mas como aproximar tais princípios e regras aos casos concretos? Como tomar decisão se os princípios forem conflitantes?

Existem três maneiras distintas de operar tal aproximação, segundo Childress (1998): aplicação, balanceamento e especificação. $\mathrm{Na}$ aplicação, o julgamento da ação concreta é derivado/ deduzido diretamente do princípio moral. Childress salienta que a maior parte das abordagens baseadas em princípios rejeita a aplicação direta por considerá-la uma forma mecânica que não ajuda a tomada de decisão quando há conflito entre princípios. No balanceamento está implícita a noção de força ou peso: qual princípio tem prioridade no momento e na situação concreta? A forma de responder a essa pergunta admite três concepções 
diferentes. Em termos ilustrativos, os princípios seriam meras recomendações, não teriam a força da obrigação moral. Para uma segunda concepção, os princípios seriam tomados como obrigações morais prima facie. Outra possibilidade seria tomá-los como regras absolutas. Observa-se, então, que há um gradiente de intensidade entre considerar princípios como meras recomendações e tomá-los como regras absolutas. $\mathrm{Na}$ especificação há intenção de tornar a regra válida nas mais abrangentes situações. São exemplos de especificação: não mentir para quem tem direito à verdade; não matar inocentes. Se não matar é inaplicável - por exemplo, quando esta é a única maneira de proteger a própria vida -, quando se especifica 'inocentes' aumentam as chances de que essa proposição seja universalmente aplicável.

Para o principialismo, o método mais adequado para aproximar os quatro princípios e as regras derivadas das situações concretas é o balanceamento, que permite tomá-los como obrigações morais prima facie, entre a regra absoluta e a mera recomendação. É preciso ter argumentos muito bons para infringir um princípio quando há conflito, pois deve-se justificar na situação concreta por que tal princípio foi rejeitado ou sobreposto a outro. É importante ressaltar que no principialismo não há, a priori, uma hierarquia entre os princípios. Assim, em determinada situação, quando as regras e princípios são contraditórios, são atribuídas prioridades válidas apenas para aquela situação concreta.

\section{Os princípios}

Embora 'autonomia' seja um termo sujeito a várias interpretações, no âmbito do principialismo ela deve ser compreendida como o governo pessoal do eu, que é livre tanto de interferências 
controladoras por parte de outros quanto de limitações pessoais que criam embaraços para a escolha, tais como a compreensão inadequada. O indivíduo autônomo age livremente de acordo com um plano escolhido por ele mesmo, da mesma forma como um governo independente administra seu território e define suas políticas. Para essa corrente, respeitar um agente autônomo é, no mínimo, reconhecer o direito dessa pessoa de ter suas opiniões, fazer suas escolhas e agir com base em valores e crenças pessoais. Esse respeito envolve a ação respeitosa, e não meramente uma atitude respeitosa. Ele exige também mais que obrigações de não intervenção nas decisões das pessoas, pois inclui o compromisso tácito de sustentar as capacidades dos outros de escolher autonomamente, diminuindo os temores e outras condições que arruínem sua autonomia.

O princípio do respeito à autonomia individual tem sua legitimidade ainda frequentemente questionada na atual prática laboral em saúde, o que dificulta sua aceitação. De fato, é bastante comum ouvir de médicos - e de outros profissionais da saúde - que "o paciente não entende o que é melhor pra ele", ou que "o paciente não estudou seis anos e mais a residência para saber medicina". Portanto, quem sabe é quem estudou. É claro que são os profissionais que detêm o saber técnico, mas é igualmente evidente - ou ao menos deveria ser - que esse saber não é capaz de estabelecer o que o paciente considera melhor para si. Aquelas palavras podem ser simplesmente um reflexo do desrespeito à autonomia do paciente - o profissional acha que sabe o que é melhor para o enfermo -, ou uma preocupação sincera do profissional em esclarecer ao máximo o paciente, "trocando em miúdos" e explicando em uma linguagem simples o que le- 
vou anos para compreender. O paciente pode não ser capaz de formular hipóteses diagnósticas sobre o seu sofrimento ou o de outra pessoa, mas pode, sem dúvida, compreender o que se passa consigo caso haja uma explicação razoável, em uma linguagem compreensível para uma pessoa do seu nível cultural.

Respeito à autonomia no cuidado da saúde ou na pesquisa significa apresentar, de forma clara e transparente, o que se passa com o sujeito e as opções que a ciência biomédica coloca a seu dispor, respeitando a sua decisão sobre o que ele entende ser melhor para si. Pressupõe, igualmente, compreender que aquilo que o saber fazer biomédico coloca à disposição - como melhor alternativa, do ponto de vista profissional - pode não ser o mais adequado aos desejos do enfermo, ao que ele tem como perspectiva de futuro, ao que ele acha razoável viver ou não viver. Respeitar a autonomia do paciente significa compreender que o sujeito pode ter perspectivas e desejos diferentes dos seus. $O$ respeito à autonomia como obrigação moral do profissional da saúde não é algo óbvio. Ao contrário, o médico em maior grau e todo profissional da saúde, em menor grau, são treinados para agir sempre em defesa da vida e do que se pensa comumente ser o melhor interesse do paciente, como se isso fosse um dado imutável, previamente conhecido. É como se houvesse um homem/mulher médio(a) que reagisse sempre da mesma maneira e, em caso de qualquer desvio em relação a essa maneira, o médico ou profissional da saúde estivesse autorizado a lhe atribuir um 'diagnóstico' ou, pior, um juízo de valor: "Não entendeu”, "Há uma doença mental” (depressão é a mais comumente mencionada) ou "É um fundamentalista religioso". Situação similar ocorre quando o sujeito expressa o 
desejo de não ser reanimado ou de não se submeter a uma cirurgia mutiladora, e o profissional é capaz de lhe dizer que não está havendo entendimento sobre a gravidade do caso ou que o sujeito está deprimido, o que faz com que sua compreensão sobre a realidade esteja "esfumaçada". Nessas circunstâncias, o que o profissional, muitas vezes, não consegue admitir é que o paciente tem outros valores a priorizar.

O princípio da não maleficência afirma a obrigação de não infligir dano a alguém intencionalmente. É um princípio que costuma gerar dificuldades para alguns profissionais da saúde, especialmente no que diz respeito à distinção com o princípio da beneficência. Atribuído a Hipócrates, o Primum non nocere (Primeiro não causar dano) é uma máxima da ética médica tradicional. O juramento do médico de Cós, repetido a cada turma que se forma em medicina, afirma que o médico aplicará os tratamentos para o bem do doente segundo seu próprio poder e entendimento, e nunca o usará para causar dano ou mal a alguém. E que entrará nas casas para o bem do doente, abstendo-se de todo dano voluntário.

Prejuízo ou dano pode ser compreendido como a ação de contrariar, frustrar ou interpor obstáculos aos interesses de alguém. O que significa dizer que há uma obrigação moral em não contrariar, frustrar ou interpor obstáculos aos interesses de alguém.

Esse princípio está bastante relacionado com os debates sobre o fim da vida que apresentaremos no Capítulo 4, em que discutimos se causar a morte a alguém é, do ponto de vista moral, mais ou menos relevante do que deixar morrer, ou se a aplicação da regra do duplo efeito - quando a morte é acelerada como consequência de ações médicas que visam não ao êxito 
letal, mas sim ao alívio do sofrimento de um paciente, como no caso do emprego de uma dose de benzodiazepínico para minimizar a ansiedade e a angústia, gerando, secundariamente, depressão respiratória e óbito - pode justificar a decisão de levar alguém à morte. Evitar causar danos a outrem constitui uma obrigação moral prima facie; sempre se pode perguntar o que significa dano para o paciente moral, ou seja, aquele que sofre a ação.

O princípio da beneficência difere da não maleficência na medida em que a beneficência implica ações positivas e a não maleficência evita ações prejudiciais; entretanto, é perceptível um continuum entre não maleficência e beneficência que torna impossível precisar o limite entre os dois conceitos. No principialismo distinguem-se dois princípios de beneficência: 'beneficência positiva' e 'utilidade'. O primeiro implica a obrigação de fazer o bem, e pode se expressar nas regras de beneficência que podem ser intuitivamente admitidas, como proteger e defender os direitos dos outros; atuar para que outros não sofram danos; eliminar as condições que causarão danos a outrem; ajudar pessoas inaptas e socorrer pessoas que estão em perigo.

Tais regras poderiam ser caracterizadas como derivadas do princípio da beneficência geral. Quando se pondera sobre o princípio da beneficência específica, entende-se a obrigação de agir de modo beneficente para determinados grupos de pessoas: obrigações para com familiares, pacientes e outros. O princípio da utilidade refere-se ao balanço de riscos e benefícios ou custos e efetividade.

No cuidado da saúde ou na pesquisa, na clínica ou na saúde pública, o princípio da beneficência tem se direcionado à 
realização de um balanço entre riscos e benefícios potenciais. A questão fundamental a responder é: quais são os possíveis benefícios e riscos para os afetados pela ação proposta? Para uma análise sobre a melhor ação para determinada circunstância é preciso identificar as ações possíveis e, para cada uma, quem serão os afetados e quais serão os possíveis benefícios e riscos delas decorrentes. Assim, pode-se fazer o balanço de benefícios e riscos e determinar aquela ação que melhor atende ao princípio da beneficência. Entretanto, convém lembrar que a análise principialista envolve os quatro princípios prima facie, o que significa que não basta que haja um balanço positivo entre riscos e benefícios, mas é necessário também que se evitem os danos, que se respeite a autonomia e que a decisão tomada seja justa, o que remete ao quarto princípio - a justiça.

Quando se pensa na aplicação do princípio da justiça às situações relacionadas ao cuidado da saúde e à pesquisa, a referência é a justiça distributiva: qual ação equaciona melhor a distribuição dos riscos e dos benefícios? Sendo necessário decidir que ação é a mais justa, como proceder? Nesses termos, podem-se distribuir os benefícios e os riscos de maneiras diversas - por exemplo, a cada um uma parte igual; a cada um a parte que atenda a suas necessidades; a cada um a parcela que merece contribuição/esforço/ papel social; e a cada um de acordo com o sorteio.

Assim, é possível pensar em uma série de critérios para a distribuição dos benefícios e dos riscos ou danos.

Após essas breves ponderações sobre o principialismo, podemos formular alguns argumentos que nos ajudarão a pensar no caso aqui proposto, o do dr. Arnaldo. 
Um primeiro princípio, o do respeito à autonomia, levaria a conversar sobre as possibilidades de tratamento com os dois e, quando isso não fosse possível, com suas famílias. Essa conversa inclui não apenas o diagnóstico preciso sobre o estado de saúde deles, mas também as alternativas de tratamento naquele hospital. Embora se pense que o razoável é imaginar que ambos desejam ser atendidos logo e imediatamente, pode ser que, com essa conversa, fique claro que o policial gostaria de ser cuidado no hospital da polícia, por já ter sido tratado nessa unidade, com sucesso, de um ferimento anterior, ou por ter receio de ser internado em qualquer hospital que não o de sua corporação, ou por qualquer outra razão. Outra possibilidade - por que não? - é que se receba a informação de que o policial é seguidor de alguma religião que imponha algum tipo de restrição no atendimento como no caso das Testemunhas de Jeová, que não aceitam, por exemplo, receber transfusões -, o que levaria à necessidade de se repensar a conduta. Ou seja, ouvir o paciente poderá trazer informações cruciais sobre como é a vida que ele acha que merece ser vivida por ele.

No caso analisado há um balanço positivo de riscos e benefícios com a intervenção médica. A cirurgia, para os dois baleados, implicará a possibilidade de viver, ao passo que se não houver intervenção muito provavelmente a morte ocorrerá em pouco tempo. $\mathrm{O}$ balanço de riscos e benefícios que propõe o principialismo não deixa dúvida de que a intervenção cirúrgica é a ação que mais benefícios poderá trazer; embora a cirurgia envolva riscos, não realizá-la implica risco de morte. É preciso examinar mais as alternativas e seus riscos e benefícios, como a transferência de 
um deles, para que se possa determinar qual dos dois teria mais chances de sobrevida com a transferência. Outra possibilidade é a realização de procedimentos fora da sala de cirurgia. Nesse caso, também riscos e benefícios têm de ser balanceados e comparados com as alternativas. Algumas vezes - e parece ser o caso do dr. Arnaldo -, a única alternativa adequada ao princípio da beneficência é a realização imediata da cirurgia em ambos os baleados. Mas, como se sabe, apenas uma sala cirúrgica está disponível.

O princípio da não maleficência está diretamente vinculado à obrigação moral de minimização dos danos. Para uma adequada avaliação dos possíveis malefícios, é necessário examinar em detalhes todas as alternativas de tratamento e seus riscos para cada um dos baleados. Pode ser que se chegue à conclusão de que um deles suportaria melhor uma alternativa paliativa no próprio ambiente do serviço de emergência. Escolhendo-se um deles para operar, o outro ficará sem o melhor tratamento (a cirurgia em ambiente cirúrgico), e isso é um malefício. Nesse caso, é fundamental observar a obrigação de tentar minimizar os danos, o que poderá implicar a escolha de alternativa que menos danos ou mais benefícios promoverá.

A aplicação do princípio da justiça ao caso implica a justa distribuição dos ônus e bônus, ou seja, o modo como serão distribuídos os recursos disponíveis para o tratamento dos baleados. Pode-se propor, como argumento em favor da hipótese de levar o policial ao centro cirúrgico, a importância dele para sua família; como é um homem de mais de 40 anos, deve ter, inclusive, filhos. Outro argumento poderá se vincular ao valor social, uma vez que o policial estava exercendo a função que a sociedade lhe atribuiu de protegê-la, de alto valor social. Veja que nesses argumentos 
não se julga o outro como bandido; quem vai dizer se o rapaz é ou não autor de um crime, se há circunstâncias que o agravem ou atenuem, é o sistema judicial. Mas se o sistema judicial já o tivesse julgado culpado, caberia ao sistema de saúde oferecer a pena? Mas, de volta ao argumento do mérito, o rapaz tem apenas 19 anos, supostamente não tem qualificação - ainda que tenha estudado -, houve menos investimento social em sua formação.

Por outro lado, poderíamos argumentar que, como o rapaz é mais jovem, ele teria maior probabilidade de se recuperar completamente, ou quase. Assim, seu balanço de riscos e benefícios seria mais favorável do que o do policial.

Outra forma de decidir qual é a distribuição mais justa seria um sorteio. Esse método pode ser visto como a pior das soluções, pois implica o reconhecimento de que não foi possível chegar a uma conclusão de outra forma, o que parece pouco provável e ainda menos aceitável.

\section{Modelo Utilitarista}

Nos termos da abordagem utilitarista, o que faz uma ação ser correta ou errada são as suas consequências. A consequência mais importante é o aumento ou diminuição da quantidade de bem-estar de todos os afetados pela ação. Nesse sentido, a melhor ação é a que produz o máximo de bem-estar. O modelo utilitarista baseia-se em três conceitos constituintes principais: consequencialismo; máximo de bem-estar; agregacionismo. Esta breve sistematização se baseará no pensamento de Richard Mervyn Hare (1998).

Enquanto na abordagem principialista propõe-se considerar os princípios que orientam a ação para uma análise ética que auxilie 
a tomada de decisão, o modelo utilitarista propõe pensar nas consequências das possíveis ações para que se possa fazer escolhas mais bem justificadas. Essas proposições, centradas nas ações e em suas consequências, demandam um conceito apropriado de ação, que corresponderia a fazer alguma diferença no curso dos acontecimentos. É muito importante que isso seja compreendido: se uma pessoa não empreendeu nenhuma mudança nos acontecimentos, então não houve ação - isto faz com que se admita como ação, também, a omissão, quando esta de fato interfere nos acontecimentos. Um exemplo usado por Hare para ilustrar a primazia das consequências do ponto de vista moral refere-se ao ato de matar alguém. Ao concordar que matar alguém é errado, todos concordarão também que puxar o gatilho (que é a ação) leva alguém à morte (matar é consequência de puxar o gatilho). Nesse caso, o que confere o estatuto de certo ou errado, de bem ou mal à ação é a sua consequência.

O máximo de bem-estar é outro conceito importante para o utilitarismo, visto que a consequência mais importante é o aumento ou diminuição da quantidade de bem-estar de todos os afetados pela ação. Como bem-estar é caracterizado como a obtenção de alto grau ou grau razoável de qualidade de vida que no todo a pessoa almeja ou prefere ter, a preferência é um elemento fundamental. Referimo-nos à preferência do afetado pela ação, e não à preferência daquele que age. É preciso também considerar a temporalidade da ação quando se trata do que Hare chama de preferências: 'agora-para-agora'; 'depois-para-depois', 'agora-para-depois'. Inclui-se, aqui, o problema do sujeito que em determinado momento afirma preferir não ser mantido vivo se estiver seriamente incapaz, e quando o tempo chega deseja muito viver, não importa como, caso em que conflita a preferência 
'agora-para-depois' com a 'depois-para-depois'. Parece simples que nesse caso a preferência 'agora-para-depois' tenha menor força. Por outro lado, fica a pergunta: quando se deve considerar a preferência 'agora-para-depois'?

O agregacionismo, último componente do modelo utilitarista, apoia-se no pressuposto de que o que vale é a 'soma' dos 'bens'. Quando há escolha entre que ações devem ser realizadas, a melhor será aquela que proverá maximamente os interesses de forma agregada (soma de todos os interesses). Isso implica não considerar a distribuição, mas sim a soma. Se uma consequência é mais bem-estar distribuído para poucos afetados e outra consequência é menos bem-estar no total, mas distribuído por um número maior de pessoas, a opção baseada no modelo utilitarista será pela ação que tem a primeira consequência. Para os utilitaristas, todos os interesses devem ser igualmente considerados, inclusive os de todos os seres sencientes, ou seja, capazes de sentir dor. Em resumo, a abordagem utilitarista propõe agir de forma a garantir o maior bem-estar para o maior número de envolvidos.

$\mathrm{Na}$ abordagem utilitarista, o caso do dr. Arnaldo seria analisado de maneira a se realizar um cálculo do maior benefício. Os dois baleados necessitam de intervenção cirúrgica para a manutenção de suas vidas. Só há uma sala cirúrgica disponível. Os quadros clínicos dos dois estão demandando cuidados. Partindo do pressuposto de que o resultado que ambos os baleados preferem ter é viver, ou seja, curar-se (ou ao menos sobreviver sem sequelas), os benefícios terão de ser somados para se verificar qual dentre as possibilidades de ação é a que representa a melhor equação de maior soma. É, sem dúvida, difícil realizar qualquer cálculo neste caso. Mas pode-se vincular a uma abordagem utilitarista o 
argumento de que o rapaz de 19 anos tem mais vida para viver do que o policial de 48. Outro cálculo pode ser o de que se o estado de José é mais grave, é ele quem deve morrer primeiro se nada for feito. Nessa perspectiva, uma alternativa pertinente poderia ser operar primeiro o paciente em estado mais grave porque assim haveria alguma chance de operar os dois. Caso se invertesse a ordem, certamente a probabilidade de que o paciente cujo quadro é mais grave venha a morrer aumentaria muito. Uma objeção a esse argumento, comumente utilizada, é a de que os pacientes em estado mais grave apresentam mais chances de morrer mesmo que sofram as intervenções demandadas. Assim, o menos grave teria mais chances de sobreviver, e caso contrário - ou seja, na opção por operar primeiro o que está em estado mais grave - as chances de os dois morrerem seriam maiores.

Por outro lado, quando se pensa em todos os afetados pela ação, constata-se que o policial tem esposa e filhos, os quais se beneficiarão com a manutenção de sua vida, pois dele dependem emocional e financeiramente, o que lhe conferiria prioridade, ao menos se não houver informação sobre o outro paciente.

Há uma grande dificuldade em implantar a proposta utilitarista, que é exatamente a necessidade de que esse cálculo agregado e comparativo de bem-estar seja feito de modo imparcial e isento (se é que isso é realmente possível...).

\section{ÉTICA DO CUIDAR}

A ética do cuidar é uma forma de compreensão do agir ético e está baseada em cinco ideias centrais: atenção moral; compreensão com simpatia; consciência das relações; acomodação e resposta. Trata-se de uma forma de consequencialismo que questiona os 
valores da imparcialidade, impessoalidade e equidade. A voz do cuidado compreende que os agentes estão envolvidos em contextos sociais particulares, relações e narrativas pessoais, que dirigem suas atenções morais a outros reais e estão abertos a compreender esses outros com simpatia e a com eles se identificar.

Lawrence Kohlberg foi um dos mais destacados pensadores que formularam a teoria do desenvolvimento moral cognitivo. Carol Gilligan, inicialmente uma de suas alunas, reconheceu na teoria de Kohlberg um viés sexista e propôs um novo olhar teórico para a compreensão do desenvolvimento moral baseado na ideia do cuidado. Gilligan publicou os resultados de sua pesquisa inicial no livro In a Different Voice, no qual buscava ressaltar que era possível entender a moralidade de outra forma, com outro olhar, o olhar do cuidado. Na perspectiva do 'cuidar', o problema moral surge quando há responsabilidades conflitantes, e para a voz da justiça quando há conflitos de direitos. E assim, a moralidade dos direitos difere da moralidade da responsabilidade em sua ênfase na separação e não na conexão, na sua consideração do individual e não do relacionamento, como elemento primário. Manning (1998) assinala que a voz da justiça compreende o indivíduo como um ser isolado, como alguém abstrato que segue regras abstratas de maneira fria e imparcial. Já a voz do cuidado compreenderia os agentes morais inseridos em seus contextos sociais específicos, com suas relações e narrativas pessoais, que dirigem suas atenções morais a outros seres reais, reconhecidos em seus contextos de vida.

Helga Kuhse, uma enfermeira australiana, critica as publicações em torno da ética do cuidar, alertando para o risco de que se entendam como naturais as distinções entre homens e mulheres, 
de modo a justificar as diferenças de poder, especialmente no trabalho em saúde. Afirma que as distinções observadas por Gilligan são engendradas socialmente e que as enfermeiras, tradicionalmente tidas como "mães substitutas" e "soldados obedientes", hoje, em uma moldura semelhante, são vistas como as defensoras dos direitos e do bem-estar dos pacientes. Para ela, essa configuração oculta as assimetrias de poder nas relações de trabalho no setor Saúde, pois o trabalho de enfermagem é pontuado por situações de subserviência e de violência moral naturalizadas por um discurso da diferença. Exemplos disso estão presentes em diversas situações que demandam uma decisão ética, e não exclusivamente técnica. Com efeito, Kuhse, por exemplo, defende que enfermeiras e enfermeiros devem ter maior autoridade profissional não só para prescrever cuidados paliativos, mas também para prescrever ordem de não ressuscitar, facilitar o suicídio assistido e a eutanásia ativa (Kuhse \& Singer, 1998).

Em suma, pode-se pensar numa ética do cuidar que proponha uma ideia de cuidado emancipadora, baseada em uma profunda compreensão das diferenças morais em genuíno respeito à autonomia de quem cuida e de quem é cuidado. Respeitar a autonomia de profissionais da saúde e de pacientes implica um profundo respeito à existência humana.

A ética do cuidar pressupõe relações humanas no interior das equipes de saúde que respeitem as especificidades técnicas de cada profissional e promovam a reflexão sobre as questões morais de forma aberta e igualitária, condições indispensáveis para que seja possível construir consensos nas situações concretas em que os dilemas morais se apresentam. 
Um caso de emergência não é muito bom para ilustrar todas as possibilidades da ética do cuidar. Ainda assim, aplicada ao caso em debate, a identificação de todos os envolvidos e suas relações, e o envolvimento de todos nas tomadas de decisões poderiam levar ao surgimento de alternativas de manejo da situação ainda não pensadas. Alguém que adote a perspectiva do cuidado para tomar a decisão no caso do dr. Arnaldo possivelmente se recusaria a fazer a opção entre os dois com base em critérios de justiça. Entendendo que pessoas vivem em famílias e que essas relações reais de cuidado não são imparciais, impessoais ou iguais, adeptos da ética do cuidado propõem um experimento para estimular a reflexão: 'Como tratar as pessoas na sociedade quando se imagina que todas são parentes?', ou, adaptando a proposição ao caso em questão: 'Como resolver o dilema do dr. Arnaldo quando se descobre (ou se considera) que ambos os pacientes são seus parentes?'.

\section{BIOÉTICA DA PROTEÇÃO}

A bioética da proteção, proposta originalmente na América Latina por Fermin Roland Schramm e Miguel Kottow (2001), é baseada na recuperação do conceito de ética, entendido em seu sentido mais arcaico: guarida, abrigo e proteção. A bioética da proteção traz a marca de uma bioética que nasce em países periféricos, com uma população empobrecida, com poucos recursos. Questiona especialmente o principialismo quando aqueles que o aplicam carregam nas tintas no princípio do respeito à autonomia. A exaltação da autonomia, quando se pensa nas populações desassistidas da América Latina, por exemplo, carece de sentido, pois nessas sociedades predominam relações 
profundamente assimétricas. Priorizar a autonomia dos sujeitos de pesquisa, por exemplo, em detrimento de outras obrigações morais sem levar em conta que esses sujeitos são pessoas com um grau de educação formal muito baixo, com problemas de acesso aos serviços de saúde, muito empobrecidos, vivendo em ambientes que expõem a saúde a riscos que seriam impensáveis em nações desenvolvidas da Europa, em países com baixo grau de formalização de regras, pode muitas vezes se configurar como uma exploração da vulnerabilidade desses indivíduos. Ou seja, com base em estratégias clientelistas e aproveitando-se do baixo nível de organização dessas populações, reforça-se a exploração, ainda que aparentemente se estimule sua autonomia. O que lhes falta para exercer sua autonomia pode ser dito em uma expressão paulofreireana - tornarem-se emancipados. O que queremos dizer é que haverá exploração da vulnerabilidade quando o argumento para a realização de uma pesquisa estiver baseado na autonomia individual de pessoas que não têm acesso a medicamentos, sequer a serviços de saúde. Nesse caso, uma população destituída de tudo não poderá ser encarada como livre para fazer escolhas como um americano médio ou um francês. A pessoa se submete a qualquer pesquisa se com isso ela obtiver atendimento.

A bioética da proteção entende que o contexto socioeconômico no qual se situa a população, marcado por grandes desigualdades, precisa ser levado em conta nas decisões de saúde pública nas quais a proteção da população mais suscetível ou descapacitada ou vulnerada deve ser a obrigação moral que orienta as ações. Colocar as desigualdades no centro da análise bioética, quando passamos a situações da assistência à saúde ou pesquisa, implica considerar as relações muito assimétricas entre as populações 
destituídas e os profissionais da saúde, o que significa afirmar a obrigação moral de proteger essa população. A proteção não deve ampliar desigualdades, mas o paternalismo típico assim o faz, por simplesmente impedir que as pessoas tomem as suas próprias decisões. Proteger significa considerar as desigualdades e usar todos os recursos para que as pessoas possam compreender suas situações e decidir segundo seus genuínos interesses, com o máximo de liberdade; significa compreender as situações de assistência e pesquisa imersas em conflitos de interesses que devem ser identificados e minimizados ativamente. Proteger significa contribuir para a emancipação de indivíduos e coletividades.

Neste ponto convém fazer uma distinção entre a bioética da proteção e o paternalismo. Embora seja possível compreender a proteção proposta por esta corrente como apenas uma versão 'branda' do paternalismo, a bioética da proteção não pode ser confundida com o paternalismo médico, que historicamente tem levado os profissionais a assumir decisões em nome dos melhores interesses dos pacientes. A proteção proposta não nega a autonomia dos sujeitos. Mas ao tratar de pessoas cujas capacidades de exercer a autonomia estejam prejudicadas, ela busca de fato (re)conquistar as condições necessárias para seu exercício. Enfocar as questões que permeiam o cotidiano da assistência à saúde significa pensar os dilemas e problemas éticos e propor soluções entre o paternalismo e a exploração da vulnerabilidade. Pode-se afirmar, portanto, que a proteção tem uma perspectiva emancipadora para os sujeitos.

A bioética da proteção foi proposta inicialmente como um referencial teórico para a resolução de díspares problemas bioéticos, especialmente no campo da saúde pública - preconizando-se 
a implementação de políticas embasadas em um "princípio de proteção" (Schramm \& Kottow, 2001: 949) -, ainda que se possa também mencionar as questões atinentes ao início da vida, ao fim da vida, à ética em pesquisa envolvendo seres humanos e aos limites da biotecnociência (Schramm, 2005b).

\section{OUTRAS CORRENTES}

Existem outros marcos conceituais da bioética contemporânea que oferecem um arsenal teórico e metodológico, os quais, apesar de úteis para a apreciação dos problemas morais - como o caso do dr. Arnaldo -, deixamos de apresentar aqui pelas limitações de espaço que uma publicação como esta impõe. Faremos referência a eles ao final do livro, quando apresentaremos algumas sugestões de leituras complementares. Referimo-nos especialmente à bioética liberal, apresentada por Hugo Tristram Engelhardt Jr.; à ética deontológica, tão importante para o nosso campo inclusive por causa dos códigos de ética profissionais, fundamentada nos trabalhos do filósofo Immanuel Kant. Fizemos referência também à ética das virtudes, em geral associada ao pensamento de Edmund Pellegrino e David Thomasma; e à chamada casuística, cuja maior expressão é Albert R. Jonsen. Entre as formulações nacionais, não poderíamos deixar de registrar a chamada bioética da intervenção, desenvolvida por Volnei Garrafa, Dora Porto e seus colegas em Brasília, bem como a proposta, em construção, de Rodrigo Siqueira-Batista, um dos autores deste livro, de uma ética para todos os seres.

Cada uma das perspectivas discutidas neste capítulo gera argumentos diferentes, mas nem sempre dão suporte a decisões diferentes. $\mathrm{O}$ caso aqui proposto constitui um verdadeiro 
dilema, pois nele não se pode, em princípio, estabelecer qual é a decisão mais correta. A maioria dos indivíduos - racionais e razoáveis - seria capaz de dizer que a decisão do dr. Arnaldo é extremamente difícil e que há bons argumentos a favor e contra a decisão anunciada. É justamente na construção desses argumentos que cada uma das correntes aqui apresentadas, como exemplos, poderá contribuir. 